\title{
Zur Notation:
}

- Objektsprachliche Einheiten (z.B. besprochene Wörter, Wortgruppen/ Syntagmen) werden in Kursivschrift gesetzt.

- Zitate aus dem Textkorpus oder aus sonstiger Literatur erhalten doppelte Anfuihrungsstriche.

- Teilbedeutungen als semantische Angaben werden, wenn sie Bedeutungsangaben $\mathrm{zu}$ bestimmten objektsprachlichen Ausdrücken sind, gemäß der philologisch-sprachwissenschaftlichen Tradition in einfache Anführungsstriche gesetzt.

- $\quad$ Anmerkung zur juristischen Zitierweise: Kommentartexte zu einzelnen Paragraphen werden üblicherweise nach Randnummern (Rdn.) zitiert. Die Kennzeichnung „vor” bedeutet, dass es sich um eine Rdn. der einleitenden Erläuterungen zu den jeweiligen Ausführungen vor jedem $\S$ handelt. 